\title{
Students Exposure to Radio Frequency Electromagnetic Fields in Marmara University
}

\author{
Fulya KUNTER \\ Marmara University, Faculty of Engineering, Department of Electrical and Electronics Engineering, 34722, \\ Kadıköy / ISTANBUL
}

\begin{abstract}
In recent years, there has been increasing public concern about the health implication of electromagnetic (EM) wave exposures due to the electronic sources. For this reason, various public organizations in the world have been established safety guidelines. In this study, electric field strength values are measured at 44 different location points of Marmara University in Göztepe Campus. In addition to the spot measurements, 24 hours measurement is also done to analyze the variation of electric field strength values. The results show that the measured electric field strength values are below the recommended international standard limits.
\end{abstract}

Keywords: Electromagnetic Pollution, Measurements, Radio Frequency Radiation.

\section{Introduction}

With the rapid growth of new technologies, there has been a considerable raise of exposure to radio frequency (RF) electromagnetic fields (EMF) [1]. Beside radars, radio, broadcast transmitters and phone base stations are among the most powerful, high-frequency sources of EMFs. Because RFs are invisible and imperceptible, individuals cannot directly determine at what level they are exposed to RF EMF. There are therefore significant challenges in assessing the exposure of individuals in the general population from RF signals, including the number and range of sources involved, and the effect of the environment on signal strengths as people move around.

To evaluate personal exposure to RF EMF in daily life, recently developed exposure meters are useful and have been recommended $[1,2]$. Radiation measurement probes are used in several studies [1, 3-10] in which they contribute to total exposure from all RF EMF sources in different locations during everyday life activities. In addition, more detailed studies have been conducted using spot measurements at the homes of study participants [11, 12], 24 hours personal measurements [4-7], measurements in different microenvironments [3] or modeling of mobile phone base station or broadcast transmitter radiation [13-15].

Some of the studies are population surveys where the personel exposure distribution in the population of interest is determined in different countries. Mantiply et. al. has made a summary of data from a number of studies on the range of RF field levels associated with a 
variety of environmental studies [16]. Frei et. al. investigated the levels, the sources and the variability of exposure to environmental RF EMF in a group of adult volunteers living in a Swiss city using personal exposimeters [17]. Viel, et. al. assesses RF exposure on a population basis in France, checks its variability with time, location and activity, and clarifies the relative contribution of different sources to the total exposure [18]. [19] compares personal RF EMF exposure in different microenvironments between urban areas in Belgium, Switzerland, Slovena, Hungary, and the Netherlands. Moreover, in another study, the potential health effects from telecommunication emissions in Greece is assessed with respect to location and time [20].

The ultimate goal of this research work is to survey RF EMF exposure levels in Marmara University Göztepe Campus. The objective of this contribution is the evaluation of the EMF exposure assessment of the possible health hazards for technical personnel and students in the university. In Section 2, the details of the exposimeter that is used in the measurements as well as the measurement methods are presented. Section 3 depicts the results of RF EMF spot and 24 hours measurements on the google map of the campus. The study is concluded with Section 4 describing the discussion of the method, and comparisons with ICNIRP Guidelines.

\section{Measurement Materials and Methods}

Measurements have been carried out in Marmara University, Göztepe Campus using NBM 550 , personal exposure meter. NBM 550 is a portable measurement device which covers 100 $\mathrm{kHz}$ to $3 \mathrm{GHz}$ frequency range with the isotropic probe, EF-0391.

As an initial survey, electric field strengths have been measured at points where the technical staff and students spend most of the time during working hours in the university. The detailed analysis has been conducted at the points where the maximum field strength values are noted. These locations are reported as Sport Areas, Student and Guest Parking Area, Handan Ertuğrul Girl Domitory, and Mechatronic Building in the university. Detailed analysis has been performed at different heights relative to the ground as well as at different distances from the point where the maximum field strength has been noted.

Following Narda instructions the probe was never closer than the distance of $20 \mathrm{~cm}$ from the metallic objects and the estimated source of radiation in order to avoid mutual coupling between the probe and the source and other measuring irregularities. To minimize the effects of the ambient sources, appliances and equipments in the area of the device under test were turned off. This survey is repeated five times in a day. Spot measurements were done at fixed locations with the measurement device.

During the measurements, the broadband probe/instrument was held in an extended arm as far as possible away from the body to minimize the effect of the human body on the electric field distribution. Six minute averaging was not done, since the measured values were stable during the measurements. Instead, the maximum value in one minute was taken as the result of the measurement.

\section{Results and Discussion}

Spot measurements were done at 44 different locations in Goztepe Campus both on a weekday and a weekend day. Because measured exposure levels on the work day was higher than the weekend day, only the work day's measurements were given in this study. The 
maximum root-meansquare (RMS) value of the field strength were recorded at each measurement points.

Measurement results are given in Figure 1 and Figure 2 in colors which corresponds to electric and magnetic field strength ranges, respectively. Field intensity is shown in units of volts/meter for electric field strength and in amperes/meter for magnetic field strength. The highest mean values were recorded for outdoor sports area and Handan Ertugrul girl dormitory in the campus. Electric field strengths at an outdoor area were typically 2 to 2.5 $\mathrm{V} / \mathrm{m}$, and at girl dormitory 1.7 to $2 \mathrm{~V} / \mathrm{m}$. Numbers in the figures are the building names which are tabulated in Table 1.

The detailed measurements are performed for Outdoor Sports Area and Handan Ertugrul Girl Dormitory buildings. Their locations in Göztepe Campus are shown on the map in Figure 3. Firstly, the electric field values have been measured all around the outdoor sports area. At the point where the maximum field value is noted, that location is taken as a reference point. As it is clearly seen in Figure 4, that reference point is shown with $0 \mathrm{~m}$ range. The colors in the figure corresponds to different height levels where the probe location is moved to $0 \mathrm{~m}$ to $2 \mathrm{~m}$ in $0.5 \mathrm{~m}$ intervals. As indicated in the figure, as the height rises, the electric field strength values are also climbing, in addition as the distance increases the electric field values gradually decreases. Because the purpose of this study is to analyze the health effects of students, the measurements above the humans' height is not considered. 

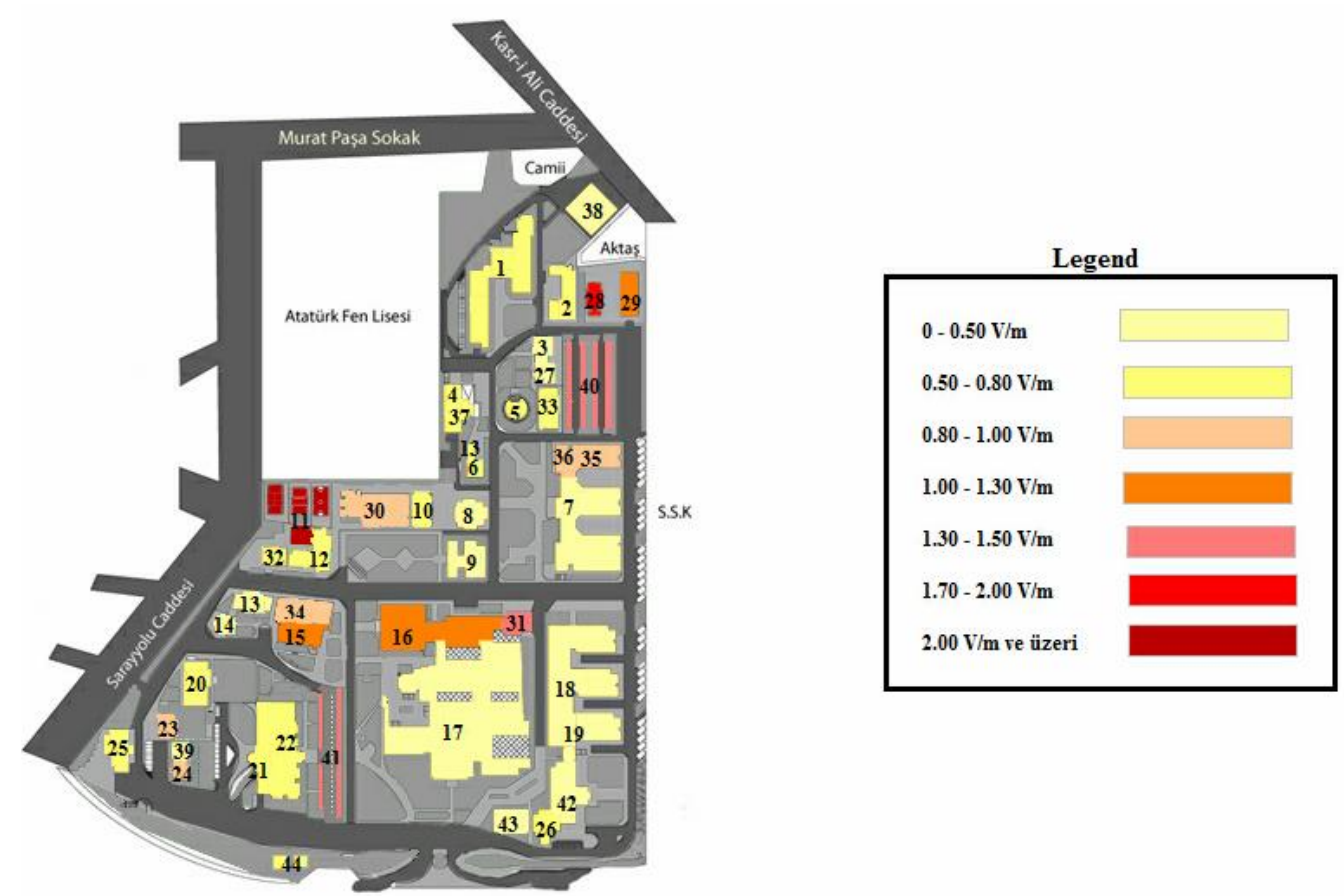

Figure 1. The measured electric field values in Goztepe Campus, Marmara University
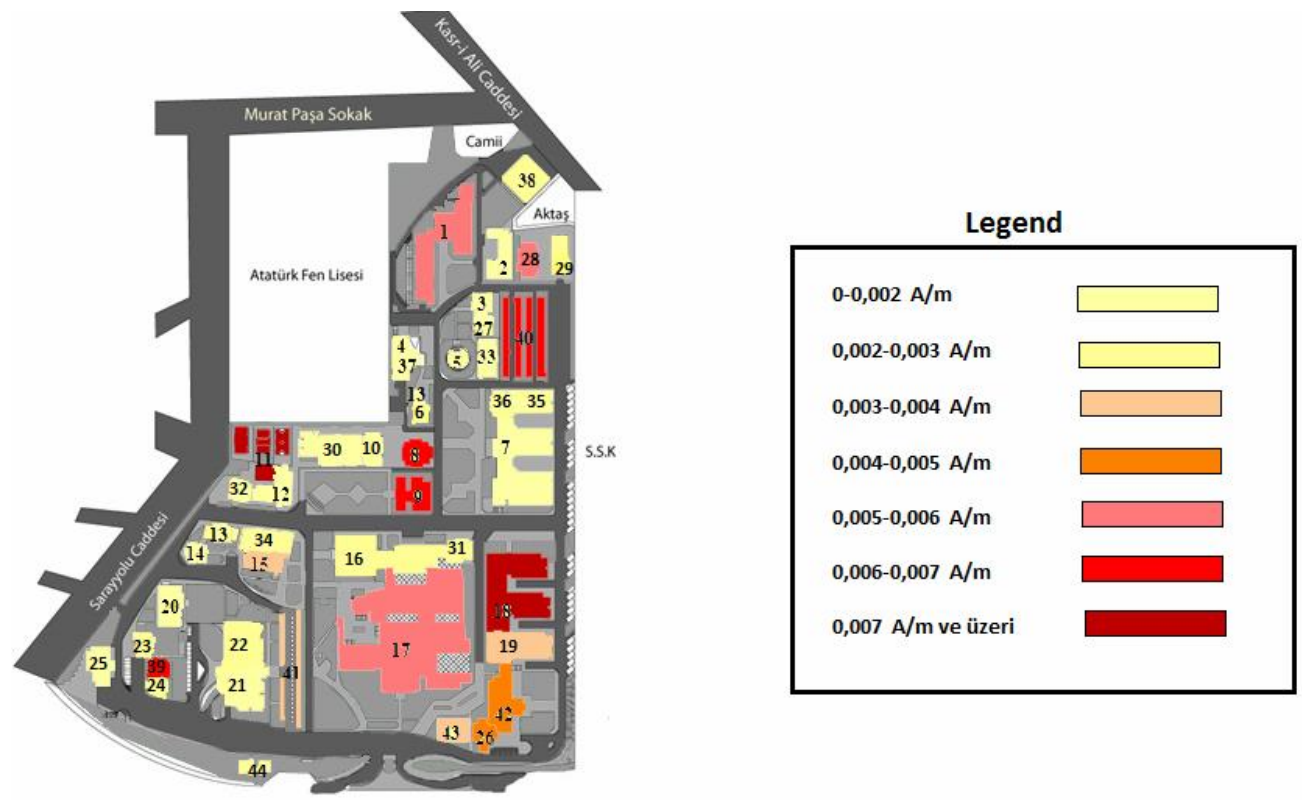

Figure 2. The measured magnetic field values in Goztepe Campus, Marmara University 
Table 1. Building names in Goztepe Campus

\begin{tabular}{|c|c|c|c|}
\hline No & Building Names & No & Building Names \\
\hline 1 & A.F.E. School of Foreign Languages & 23 & Institute of Turkish Studies \\
\hline 2 & Faculty of Engineering D Block & 24 & European Union Institute \\
\hline 3 & Medico-Social Center & 25 & Guet House \\
\hline 4 & Campus Dining Hall & 26 & Revolving Fund Administration \\
\hline 5 & 125th Year Theatre & 27 & Health, Culture, Sports Administrative Dept. \\
\hline 6 & Historical Turkish Bath & 28 & Handan Ertugrul Girl Dormitory \\
\hline 7 & Faculty of Arts and Sciences & 29 & Prosthetics Orthotics Rehabilitation Center \\
\hline 8 & Faculty of Engineering B Block & 30 & Market Area \\
\hline 9 & $\begin{array}{l}\text { Faculty of Engineering } \\
\text { Administrative Building }\end{array}$ & 31 & Mechatronic Systems Laboratory \\
\hline 10 & Faculty of Engineering C Block & 32 & School of Banking and Insurance \\
\hline 11 & Outdoor Sports Area & 33 & The Student Information Processing Area \\
\hline 12 & Faculty of Economics & 34 & Institute of Banking and Insurance \\
\hline 13 & $\begin{array}{l}\text { School of Foreign Languages } \\
\text { Administrative Building }\end{array}$ & 35 & Institute of Pure and Applied Sciences \\
\hline 14 & $\begin{array}{l}\text { School of Foreign Languages } \\
\text { Classrooms }\end{array}$ & 36 & Institute of Educational Sciences \\
\hline 15 & Dr. İbrahim Uzumcu Auditorium & 37 & Mustafa Necati Auditorium \\
\hline 16 & Indoor Sports Hall & 38 & Heat Power Station \\
\hline 17 & Ataturk Faculty of Education & 39 & International Office \\
\hline 18 & Faculty of Technical Education & 40 & Student and Guest Parking \\
\hline 19 & $\begin{array}{l}\text { Vocational School of Technical } \\
\text { Sciences }\end{array}$ & 41 & Academic Member Parking Lot \\
\hline 20 & Ozmen Aktar Girl Dormitory & 42 & Revolving Fund Accountancy Office \\
\hline 21 & Rector's Office & 43 & Life-Long Learning Programme Center \\
\hline 22 & Central Library & 44 & Post Office \\
\hline
\end{tabular}




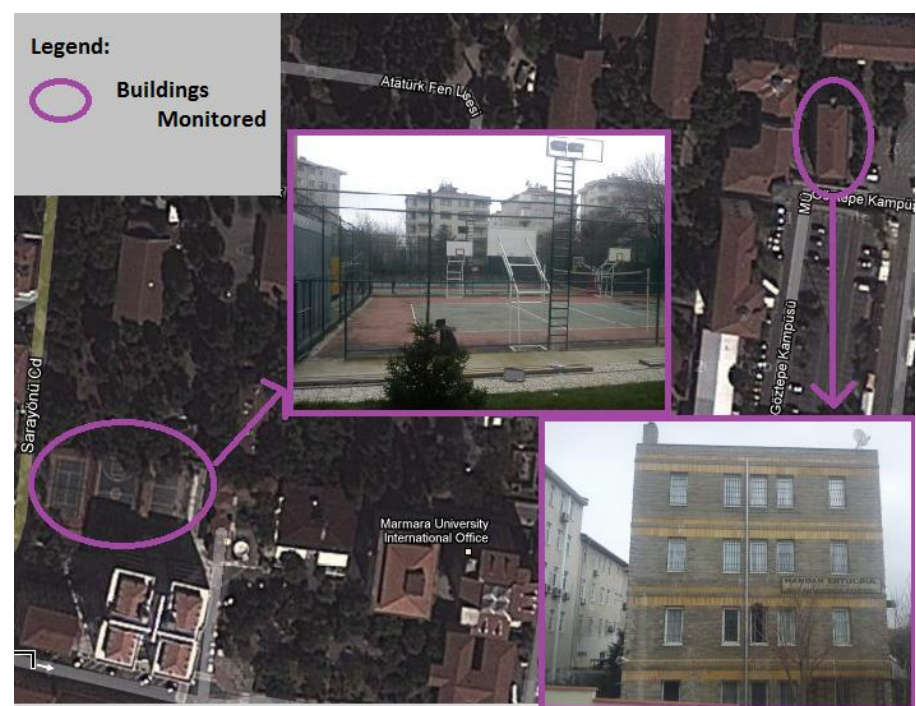

Figure 3. The view of Outdoor Sport Areas and H.E. Girl Dormitory buildings in the map

Outdoor Sports Area Electric Field Measurement

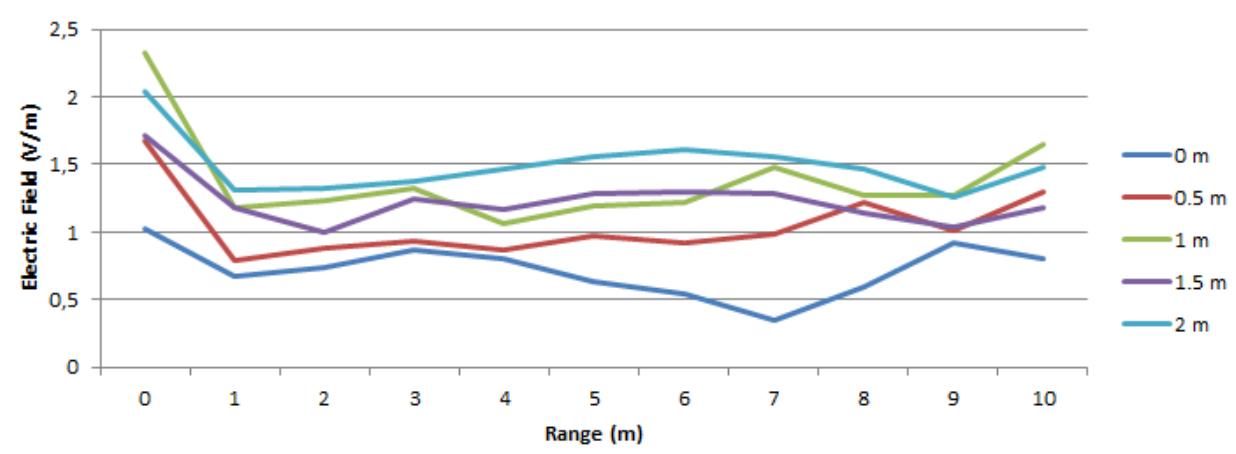

Figure 4. Electric field measurements for Outdoor Sports Area

Secondly, electric field measurements for Handan Ertugrul Dormitory are monitored for 24 hours. According to the measurement results which are given in Figure 5, at midnight and in the morning time intervals electric field strength values fluctuate in between $1.28 \mathrm{~V} / \mathrm{m}$ and $1.18 \mathrm{~V} / \mathrm{m}$. In the evening the values decline to $1.1 \mathrm{~V} / \mathrm{m}$ and then stabilizes in late evenings.

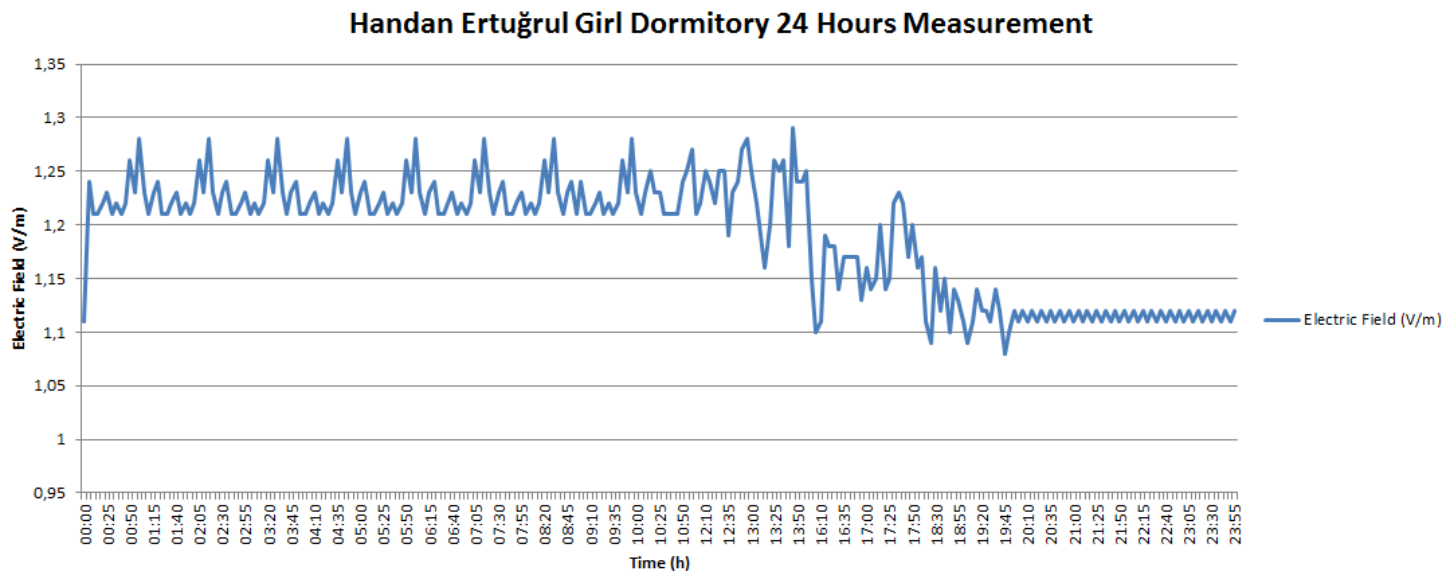

Figure 5. 24 Hours electric field measurement for Handan Ertugrul Dormitory 


\section{Conclusions}

Measurements of field strengths using the exposimeters at different points have been made in Marmara University, Goztepe Campus. The intention of presenting this study was to quantify exposure levels to RF from different sources such as mobile phone base stations, mobile phone handsets, DECT cordless phones for students in Marmara University.

All sets of measurements which were performed in Marmara University, Goztepe Campus, were made at the point where the maximum reading was achieved using the hand held devices at RF ranges. All represented RMS levels of electric and magnetic field strength expressed in $\mathrm{V} / \mathrm{m}$ and $\mathrm{A} / \mathrm{m}$. The maximum electric field measurements were $2.4 \mathrm{~V} / \mathrm{m}$ at a distance of $1 \mathrm{~m}$ from outdoor sport area and $1.28 \mathrm{~V} / \mathrm{m}$ for Handan Ertuğrul Dormitory. When the results are compared with the ICNIRP guidelines safety limits (Table 3), it is obviously seen that the measured values complied with the limits.

To our knowledge, this is the first study to assess RF EM field exposure by combining personal measurements with spot and full day measurements in a university. However, with measurement results for different exposure locations, we expect the results to become more useful for risk assessment of students, personnel and instructor studying close to EMF sources. The data presented herein should be especially useful in understanding the fall-off of the electric field from any appliance with distance.

Table 3. ICNIRP reference limits for RF fields

\begin{tabular}{|l|l|l|l|l|}
\hline & $\begin{array}{l}\text { Frequency (f), } \\
\mathrm{MHz}\end{array}$ & $\begin{array}{l}\text { Electric field } \\
\text { Strength, V/m }\end{array}$ & $\begin{array}{l}\text { Magnetic Field } \\
\text { Strength, A/m }\end{array}$ & $\begin{array}{l}\text { Power Flux } \\
\text { Density, mW/cm }\end{array}$ \\
\hline Occupational & $0.3-3$ & 632 & 1.6 & 100 \\
& $3-30$ & $1897 / \mathrm{f}$ & $4.74 / \mathrm{f}$ & $(30 / \mathrm{f})^{2}$ \\
& $30-300$ & 63.2 & 0.16 & 1.0 \\
& $300-1500$ & $3.65 \mathrm{f}^{1 / 2}$ & $0.009 \mathrm{f}^{1 / 2}$ & $\mathrm{f} / 300$ \\
& $1500-100000$ & 14.1 & 0.35 & 5.0 \\
\hline
\end{tabular}

\section{Acknowledgements}

This work was sponsored by Marmara University Research Foundation FEN-D-120514-0176. The author also wishes to thank Miss. Yagmur Kirkagac and Mr. Baris V. Yildirim for their help in performing the measurements reported herein.

\section{References}

[1] Neubauer, G., Feychting, M., Hamnerius, Y., Kheifets, L., Kuster, N. and Ruiz, I. (2007). Feasibility of future epidemiological studies on possible health effects of mobile phone base stations. Bioelectromagnetics, 28, 224-230.

[2] Ahlbom, A., Bridges, J. de Seze, R., Hillert, L., Juutilainen, J. and Mattsson, M. O. (2008). Possible effects of electromagnetic fields (EMF) on human health: opinion of the 
scientific committee on emerging and newly identified health risks (SCENIHR), Toxicology 246, 248-250.

[3] Joseph, W., Vermeeren, G., Verloock, L., Masache Heredia, M. and Martens, L. (2008). Characterization of personal RF electromagnetic field exposure and actual absorption for the general public. Health Physics, 95, 317-330.

[4] Kühnlein A, Heumann C, Thomas S, Heinrich S, Radon K. (2009). Personal exposure to mobile communication networks and well-being in children - a statistical analysis based on a functional approach. Bioelectromagnetics.

[5] Thomas, S., Kühnlein, A., Heinrich, S., Praml, G., Nowak, D., von Kries, R. and Radon, K. (2008). Personal exposure to mobile phone frequencies and well-being in adults: a crosssectional study based on dosimetry. Bioelectromagnetics, 29, 463-470.

[6] Thuroczy, G., Molnar, F., Janossy, G., Nagy, N., Kubinyi, G., Bakos, J. and Szabo, J. (2008). Personal RF exposimetry in urban area. Annual Telecommunication, 63, 87-96.

[7] Viel, J. F., Clerc, S., Barrera, C., Rymzhanova, R., Moissonnier, M., Hours, M. and Cardis, E. (2009). Residential exposure to radiofrequency fields from mobile phone base stations, and broadcast transmitters: a populationbased survey with personal meter. Occupational Environmental Medicine, 66, 550-556.

[8] Radon, K., Spegel, H., Meyer, N., Klein, J., Brix, J., Wiedenhofer, A., Eder, H., Praml, G., Schulze, A., Ehrenstein, V., Von Kries, R., Nowak, D. (2006). Personal dosimetry of exposure to mobile telephone base stations? An epidemiologic feasibility study comparing the Maschek dosimeter prototype and the Antennessa DSP-090 system. Bioelectromagnetics 27 (1), 77-81.

[9] Schüz, J. and Mann, S. (2000). A discussion of potential exposure metrics for use in epidemiological studies on human exposure to radiowaves from mobile phone base stations. J. Expo. Sci. Env. Epid. 10, 600-605.

[10] Bornkessel, C., Schubert, M., Wuschek, M. and Schmidt, P. (2007). Determination of the general public exposure around GSM and UMTS base stations. Radiat. Prot. Dosim. 124, 4047.

[11] Hutter, H. P., Moshammer, H., Wallner, P. and Kundi, M. (2006). Subjective symptoms sleeping problems, and cognitive performance in subjects living near mobile phone base stations. Occup. Environ. Med. 63, 307-313.

[12] Berg-Beckhoff, G., Blettner M., Kowall, B., Breckenkamp, J., Schlehofer, B., Schmiedel, S. (2009). Mobile phone base stations and adverse health effects: phase 2 of a cross-sectional study with measured radio frequency electromagnetic fields. Occup. Environ. Med. 66, 124130. 
[13] Ha, M., Im H, Lee, M., Kim, H.J., Kim, B.C., Gimm, Y.M., et al. (2009). Radiofrequency radiation exposure from AM radio transmitters and childhood leukemia and brain cancer. Am. J. Epidemiol. 166, 270-279.

[14] Neitzke, H. P., Osterhoff, J., Peklo, K. and Voigt, H. (2007). Determination of exposure due to mobile phone base stations in an epidemiological study. Radiat. Prot. Dosim. 124, 3539.

[15] Breckenkamp, J., Neitzke, H.P., Bornkessel, C., Berg-Beckhoff, G. (2008). Applicability of an exposure model for the determination of emissions from mobile phone base stations. Radiat. Prot. Dosimetry. 131(4), 474-481.

[16] Mantiply, E. D., Pohl, K. R., Poppell, S. W., and Murphy, J. A., (1997), Summary of measured radiofrequency electric and magnetic fields $(10 \mathrm{kHz}$ to $30 \mathrm{GHz})$ in the general and work environment. Bioelectromagnetics. 18, 563-577.

[17] Frei, P., Mohler, E., Bürgi, A., Fröhlich, J., Neubauer, G., Braun-Fahrländer, C., Röösli, M., and the QUALIFEX team, (2009), A prediction model for personal radio frequency electromagnetic field exposure. Sci. Total Environ. 408, 102-108.

[18] Viel, J. F., Cardis, E., Moissonnier, M., Seze, R., Hours, M., (2009), Radiofrequency exposure in the French general population: band, time, location and activity variability. Environ. Int. 35, 1150-1154.

[19] Joseph, W., Frei, P., Roösli, M., Thuroczy, G., Gajsek, P., Trcek, T., Bolte, J., Vermeeren, G., Mohler, E., Juhasz, P., Finta, V., and Martens, L., (2010), Comparison of personal radio frequency electromagnetic field exposure in different urban areas across Europe. Environ. Res. 110, 658-663.

[20] Manassas, A., Boursianis, A., Theodoros, S., and Sahalos, J. N., (2012), Continuous electromagnetic radiation monitoring in the environment: analysis of the results in Greece. Radiat. Prot. Dosimetry. 151 (3), 437-442.

[21] International Commission on Non-Ionizing Radiation Protection (ICNIRP) (1998), Guidelines for limiting exposure to time-varying electric, magnetic and electromagnetic fields (Up to $300 \mathrm{GHz}$ ). Health Phys. 41, 449-552. 